\title{
Lesões Pulmonares Associadas ao Uso do Cigarro Eletrônico
}

AUTORES: D’Almeida,P.C.V2; Silveira,M.B²; Poiano,R²; Américo,B2; Padula,A.L.2; Santos-Junior, N.G1

1Professor de Pneumologia do Centro Universitário São Camilo - SP; 2 Acadêmico curso de medicina do Centro Universitário São Camilo - SP

RESUMO: EVALI - E-cigarette or Vaping Associated Lung Injuries/llnnessess (lesões pulmonares/doenças pulmonares associadas ao cigarro eletrônico ou ao "vaping"). Difundido pela indústria do tabaco como menos prejudicial à saúde, o cigarro eletrônico ganhou espaço entre jovens. Mas seu uso vem causando síndrome emergente, com manifestações clínicas importantes e até mesmo óbito. O diagnóstico é de exclusão. $O$ tratamento é feito com cessação do uso do cigarro eletrônico e terapia empírica com corticóides, antimicrobianos e antivirais. OBJETIVO: Descrever as principais manifestações clínicas, radiológicas e anátomo patológicas em pacientes com EVALI. METODOLOGIA: Revisão narrativa sistematizada, em base de dados: Bireme, Cochrane Library, Pubmed e Scielo. Descritor utilizado: "Electronic Nicotine Delivery Systems" AND "Lung Injury". Selecionados publicações dos últimos dez anos (línguas inglesa, espanhola e portuguesa), sem restrição do tipo de estudo. 402 artigos incialmente; excluídos os repetidos em diferentes bases de dados e os que não se relacionavam ao tema ou se relacionavam com outras doenças. Por fim, 101 estudos foram utilizados. RESULTADOS: 2.668 relatos de pessoas com EVALI (até 14 janeiro 2020), média de idade 24 anos (13 a 85 anos); $66 \%$ sexo masculino; Tempo médio de uso do cigarro eletrônico de 12,8 meses (variando de 1 dia a 5 anos de uso). Manifestações clínicas: dispneia (66,5\%), tosse (64\%), febre (60\%), fadiga (40\%) e dor torácica $(35,5 \%)$. Sintomas gastrointestinais foram frequentes: vômitos $(48 \%)$, náuseas (45\%), diarréia (25\%) e dor abdominal (19\%). Cerca $25 \%$ dos pacientes apresentaram taquipneia e hipoxemia e 3,6\% hemoptise. Manifestações radiológicas: infiltrado intersticial (vidro fosco) em mais de $90 \%$ dos casos e raramente consolidações, opacidades alveolares, lesões cavitárias e bronquiectasias. Análise anatomopatológica realizada em 164 desses indivíduos, (material via broncoscopia) e achados mais frequentes: dano alveolar difuso, hemorragia alveolar; pneumonia lipoide, proteinose alveolar e BOOP em alguns casos. E 68 casos evoluíram a óbito. CONCLUSÃO: O uso do cigarro eletrônico é uma nova forma de tabagismo 
emergente, principalmente em indivíduos jovens, não isento de malefícios à saúde. O EVALI é uma síndrome de lesão pulmonar aguda, com manifestações importantes, inclusive risco de morte.

DESCRITORES: "Electronic Nicotine Delivery Systems" AND "Lung Injury"

\section{INTRODUÇÃO}

\subsection{DEFINIÇÃO}

O termo em inglês EVALI seria o E-cigarette or Vaping Associated Lung Injuries/lllnessess (lesões pulmonares/doenças pulmonares associadas ao cigarro eletrônico ou ao "vaping"). Sendo o "vaping" a aerossolização ocasionada pelo aquecimento de um líquido, que costuma conter em sua composição a nicotina, aromas, solventes e outros produtos químicos, através de um dispositivo. ${ }^{1,2,3}$

O EVALI tem sido considerada uma síndrome emergente nos últimos anos, sendo caracterizada como uma doença respiratória aguda, podendo evoluir para o óbito. ${ }^{4,5}$

Apesar dos efeitos de curto a longo prazo desses dispositivos não serem totalmente compreendidos, observa-se um aumento de usuários e consequentemente um aumento do número de casos. ${ }^{6}$

\subsection{INDÚSTRIA DO CIGARRO}

A sua introdução no mercado internacional ocorreu em 2007, ganhando espaço entre adolescentes e adultos jovens. Isso tem sido observado devido à promessa de que o cigarro eletrônico seria uma alternativa "mais saudável" ao tabagismo tradicional, por causa da menor aceitação do tabagismo social e, também à legalização do uso da maconha medicinal e recreativa. Dessa forma, ele é voltado principalmente para fumantes no processo de cessação do tabagismo e para os exfumantes, como uma alternativa às gomas de nicotina e aos adesivos transdérmicos. Entretanto, ele não é isento de efeitos colaterais. ${ }^{1}$, 7, 8, 9, 10

Inicialmente a venda desses dispositivos foi realizada virtualmente, sem regulamentos específicos e de forma ilícita. Diante desse fenômeno, surgiu um novo problema de saúde pública, pois o uso inadvertido dos cigarros eletrônicos se graças a seus consumidores acreditarem ser um produto mais seguro e menos viciante. Associado a esse fato, temos a questão da publicidade e do marketing desses 
produtos serem patrocinados e vendidos como o cigarro tradicional costumava ser, passando a ideia de que seu consumo é algo glamuroso, atraente, associado à juventude e a modernidade, com a ilusão de serem saudáveis. ${ }^{1,5,11,12}$

\subsection{FUNCIONAMENTO DO CIGARRO ELETRÔNICO}

Os cigarros eletrônicos são equipamentos movidos a bateria promovendo a aerossolização pelo aquecimento de líquidos, de uma solução chamada "e-liquid" ou "vape juice", podendo ou não conter nicotina, além de outros compostos que incluem propilenoglicol, glicerina vegetal, agentes aromatizantes e aditivos. Essa mistura é aquecida rapidamente ao ser exposta as bobinas, que podem conter ferro, cromo, carbono, níquel ou outros metais. ${ }^{13}$

Os dispositivos têm tamanhos e estilos diversos, variando entre os que se assemelham aos cigarros tradicionais e as canetas vapes, canetas para narguile, charutos, cachimbos de água entre outros. Porém a sua estrutura interna é essencialmente a mesma, contendo uma bateria de voltagem variável, um elemento de aquecimento ou bobina de aquecimento (para converter o líquido em aerossol), um reservatório para o líquido e um bocal para inalação. ${ }^{13,14}$

Embora a maioria desses sistemas eletrônicos de entrega de nicotina contenham nicotina associado a um agente aromatizante, muitos desses aparelhos contêm compostos à base de maconha que são usados para substituir a maconha tradicional. A composição do aerossol gerado depende dos ingredientes do líquido e das características elétricas do elemento de aquecimento, bem como da temperatura atingida. ${ }^{13,14}$

Mais recentemente, os cigarros eletrônicos possuem uma nova apresentação de dispositivos baseados em cápsulas, que são menores e têm a forma de uma unidade USB. Assim, o uso de cigarros eletrônicos aumentou tremendamente entre os alunos do ensino médio. ${ }^{14}$

Apesar da variedade de formas, ainda apresentam efeitos prejudiciais, que vão desde lesões térmicas relacionadas ao mau funcionamento do dispositivo até um conjunto de doenças respiratórias suspeitas. ${ }^{13}$

Figura 1: Modelo básico de cigarro eletrônico. 


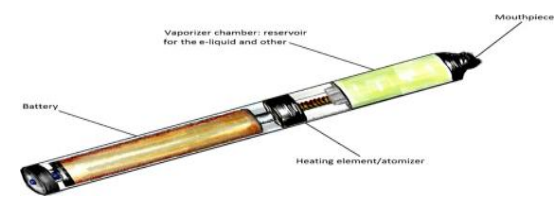

Fonte: E-Cigarette or Vaping Product-Associated Lung Injury: A Review. ${ }^{14}$

\subsection{SUBSTÂNCIAS DO CIGARRO ELETRÔNICO}

No líquido do cigarro eletrônico existem diversas substâncias com potencial nocivo para o organismo humano. Entretanto, não se sabe um componente ou ingrediente específico que cause as lesões pulmonares e devido à adição e mistura de substâncias, dificulta ainda mais a identificação do agente causal. ${ }^{15}$

Assim, os componentes majoritários do líquido são a nicotina, aromatizantes e outros aditivos. Sendo o tetra-hidrocanabinol (THC) o principal agente psicoativo da cannabis e seus cartuchos são comprados, na maioria das vezes, por revendedores ilícitos, mais rotulados como "Dank Vapes".1, 16, 17

Além das substâncias contidas no líquido, nos estudos de Mishra et al (2017) e Olmedo et al. (2018), foi visto que metais tóxicos, como níquel, chumbo e cromo estão presentes no vapor do cigarro eletrônico e são oriundos da bobina metálica responsável pelo aquecimento do líquido na produção dos aerossóis. ${ }^{18}$

Dentre elas, há os sais de nicotina podendo causar possíveis efeitos tóxicos, como envenenamento, aumentando risco de fatores adversos quando associado à inalações frequentes. Pode estar associado também à introdução do uso de cartuchos contendo extratos de THC. ${ }^{16,19,20}$

Foi visto que atualmente ocorre a comercialização cápsulas de cigarro eletrônico com sabor. Tal componente é um fator relacionado ao vício em nicotina de milhares de usuários. ${ }^{20}$

Outra substância presente é o acetato de vitamina $E$, componente que costuma estar associado a produtos contendo THC. A decomposição do acetato de vitamina $\mathrm{E}$ decorrente do aquecimento pode resultar em outros compostos tóxicos, como o ceteno. ${ }^{16,20,21}$

Uma curiosidade vista nos estudos foi que em algumas regiões dos Estados Unidos, onde a maconha recreativa era legalizada, os cartuchos de vaping contendo THC não eram contaminados com acetato de vitamina E. Isso ocorre pelo fato de que 
há incentivo financeiro para diluição do THC em estados onde a maconha é ilegal, agregando valor ao produto. ${ }^{8}$

A aspiração de substâncias ricas em óleos e lipídios, como óleo de mamona, vaselina, mentol e glicerina refletem em alterações exógenas, culminando na pneumonia lipóide. ${ }^{7,} 22$

A espectrometria de massa de diluição isotópica é um método criado pelo CDC (Centers of Disease Control and Prevention) para analisar tóxicos específicos e compostos ativos no líquido do lavado broncoalveolar. Esse procedimento pode ser usado para identificar o acetato de vitamina $\mathrm{E}$ e diferenciá-lo de outros componentes, como o óleo MCT (triglicerídeos de cadeia média), óleos vegetais (triglicerídeos de cadeia longa), destilados de petróleo (incluindo óleo mineral), terpenos diluentes, canabinóides e nicotina no fluido do lavado broncoalveolar. ${ }^{23}$

\section{OBJETIVO}

Descrever as principais manifestações clínicas, radiológicas e anátomo patológicas em pacientes com EVALI.

\section{METODOLOGIA}

Este estudo trata-se de uma revisão narrativa sistematizada, através de extensa busca na literatura em base de dados de artigos científicos como: Bireme, Cochrane Library, Pubmed e Scielo, entre os dias 5 de maio e 13 de maio do ano de 2020. O descritor utilizado na busca de artigos nessas bases foram: "Electronic Nicotine Delivery Systems" AND "Lung Injury".

Inicialmente foi feito uma busca com esse descritor no Mesh Terms. Visto a existência deste termo foi realizada uma pesquisa utilizando-o nas bases de dados escolhidas. A busca resultou em: 404 artigos encontrados. Deste total de artigos foram aplicados os critérios de inclusão e de exclusão. Foram incluídos trabalhos científicos publicados nos últimos dez anos e nas línguas inglesa, espanhola e portuguesa, sem restrição do tipo de estudo. Com base nesses critérios, foram excluídos dois artigos que não estava escrito nos idiomas selecionados (um artigo escrito em alemão e outro em tcheco), resultando em 402. Foram excluídos ainda trabalhos que se repetiam em diferentes bases de dados. Com esse critério, foram excluídos 122 artigos, totalizando 282 artigos. Além disso, foram excluídos também trabalhos que não se relacionavam 
ao tema ou que se relacionavam com outras doenças que não a Injúria Pulmonar de forma objetiva. A exclusão destes artigos foi feita através de avaliação após leitura e análise dos títulos dos que faziam menção a outras doenças que não aquela pesquisada; caso não fosse possível eliminar tais artigos, o próximo passo seria ler o resumo e se necessário, ler o texto na íntegra. Desse modo, utilizando todos os critérios de inclusão e exclusão, foram utilizados 101 estudos na produção dessa revisão narrativa.

Figura 2: Fluxograma da seleção dos artigos selecionados

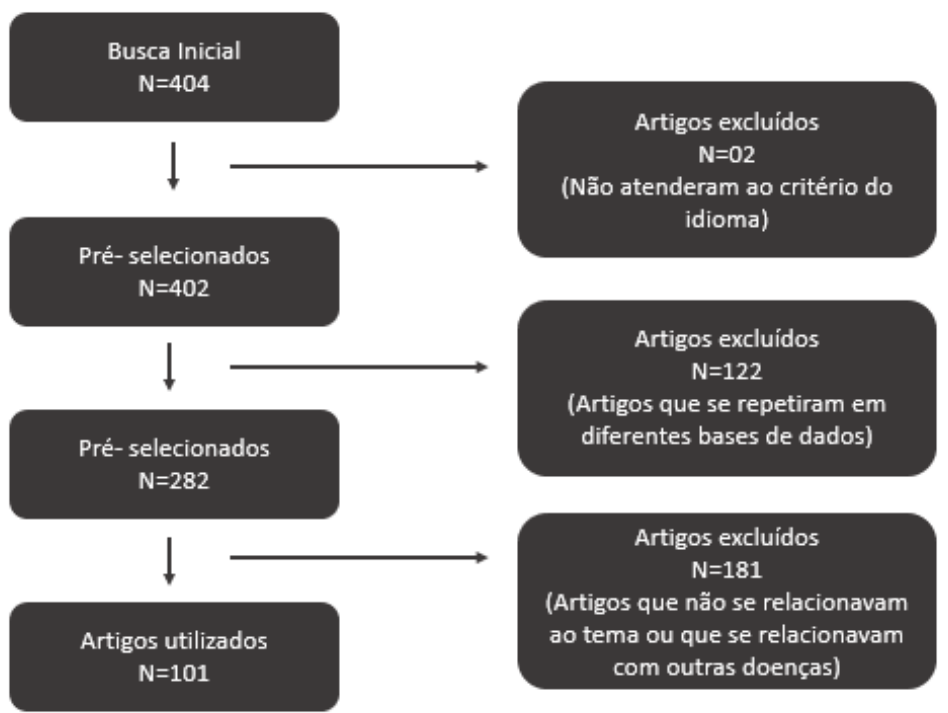

Fonte: Dados coletados pelos autores

\section{RESULTADOS}

Até 14 de janeiro de 2020, foram relatados ao CDC 2.668 casos de EVALI hospitalizados:

- $66 \%$ eram homens;

- A idade média dos pacientes era de 24 anos (13 a 85 anos);

Por categoria de faixa etária:

- $15 \%$ dos pacientes eram menores de 18 anos;

- 37\% dos pacientes tinham de 18 a 24 anos;

- $24 \%$ dos pacientes tinham de 25 a 34 anos; e

- $24 \%$ dos pacientes tinham 35 anos ou mais. 
E até 18 de fevereiro de 2020, 68 mortes por EVALI foram confirmadas.

Dados específicos sobre o uso das substâncias utilizadas foram relatados em 2.022 pacientes hospitalizados:

- $82 \%$ relataram o uso de produtos contendo THC e $33 \%$ uso exclusivo de produtos contendo THC.

- $57 \%$ relataram usar produtos contendo nicotina e $14 \%$ uso exclusivo de produtos contendo nicotina.

O tempo médio de uso do cigarro eletrônico foi de 12,8 meses (variando de 1 dia a 5 anos de uso).

As manifestações clínicas encontradas foram: dispneia (66,5\%), tosse (64\%), febre $(60 \%)$, fadiga $(40 \%)$ e dor torácica $(35,5 \%)$. Sintomas gastrointestinais foram frequentes: vômitos (48\%), náuseas (45\%), diarreia (25\%) e dor abdominal (19\%). Cerca $25 \%$ dos pacientes apresentaram taquipneia e hipoxemia e 3,6\% hemoptise. (Figura 5)

Figura 3: Principais manifestações clínicas vistas no EVALI

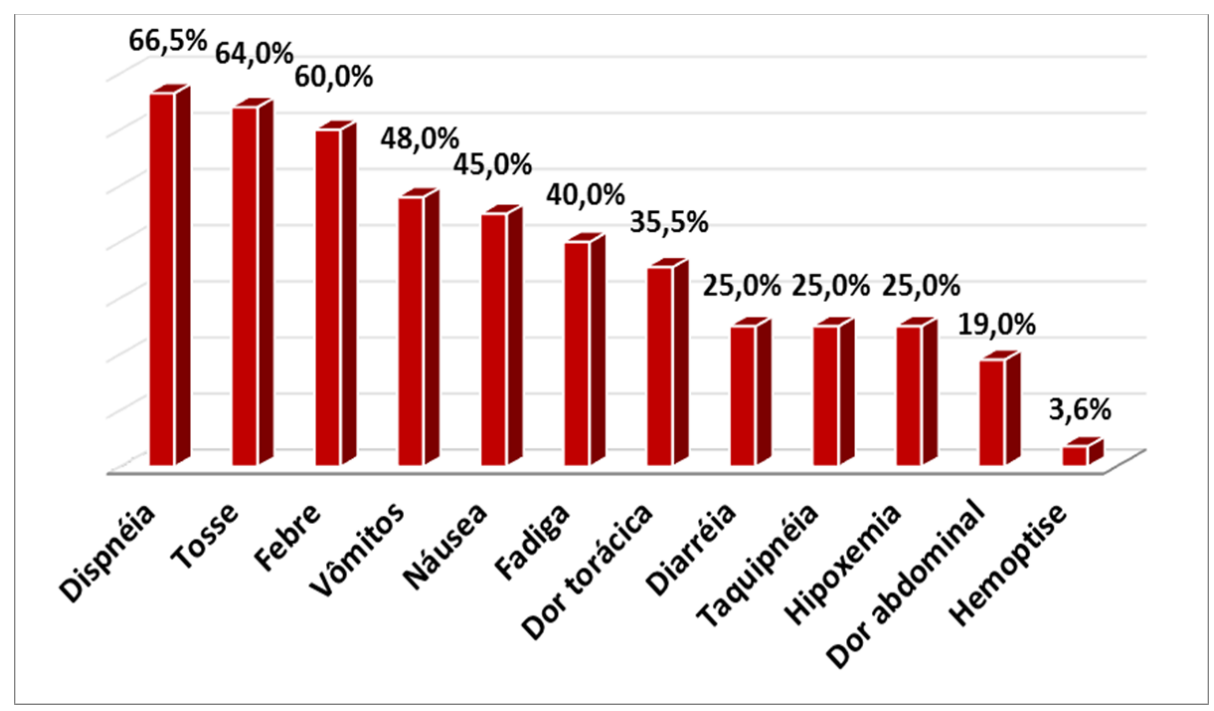

Fonte: Dados coletados pelos autores

Em relação às manifestações radiológicas: infiltrado intersticial (vidro fosco) em mais de $90 \%$ dos casos e raramente consolidações, opacidades alveolares, lesões cavitárias e bronquiectasias.

Análise anatomopatológica foi realizada em 164 desses indivíduos, (material via broncoscopia) e achados mais frequentes: dano alveolar difuso, hemorragia 


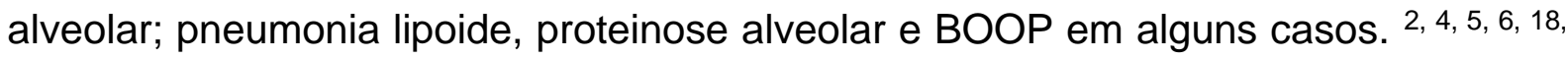
$24,25,26,27,28,29,30,31,32,33,34,35,36,37,38,39,40,41,42,43,44,45,46,47,48,49,50,51,52,53,54,55,56,57$, $58,59,60,61,62,63,64,65,66,67,68,69,70,71,72,73,74,75,76,77,78,79,80,81,82,83,84,85,86$

\section{Discussão}

Durante muitos anos, o ato de fumar o tabaco era tido como um passatempo glamuroso, caracterizado como um sinônimo de modernidade. Apesar dos estudos demonstrarem que tal hábito é prejudicial à saúde, ainda assim surgem novas formas de tabagismo e com isso o surgimento de novas doenças. ${ }^{87}$

Atualmente, desenvolvido pela indústria do cigarro, temos o advento dos cigarros eletrônicos como uma nova forma de tabagismo. E com ele, surgiu o EVALI, - E-cigarette or Vaping Associated Lung Injuries/lllnessess (lesões pulmonares/doenças pulmonares associadas ao cigarro eletrônico ou ao "vaping"), objeto de estudo deste trabalho. ${ }^{87}$

Em 2019, mais de 5 milhões de alunos do ensino fundamental e médio nos EUA usaram cigarros eletrônicos nos últimos 30 dias, incluindo 10,5\% dos alunos do ensino médio e $27,5 \%$ dos alunos do ensino médio.

Em 2017, 2,8\% dos adultos norte-americanos eram usuários atuais de cigarros eletrônicos.

Em 2015, entre os usuários adultos de cigarros eletrônicos em geral, 58,8\% também eram fumantes regulares atuais, 29,8\% eram ex-fumantes regulares e 11,4\% nunca haviam sido fumantes regulares.

Entre os usuários atuais de cigarro eletrônico com 45 anos ou mais em 2015, a maioria era fumante regular ou ex-fumante e 1,3\% nunca havia fumado. Em contraste, entre os usuários atuais de cigarros eletrônicos com idade entre 18 e 24

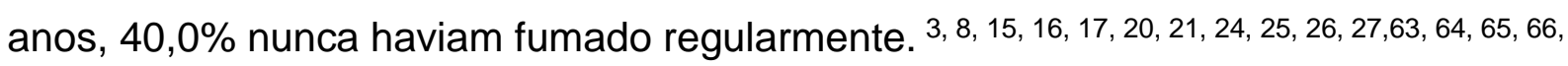
$67,68,69,70,71,72,73,74,75,76,77,78,79,80,81,82,83,84,85,86$

\subsection{FISIOPATOLOGIA}

Os mecanismos de lesão pulmonar desencadeados pelo uso de cigarro eletrônico ainda não estão bem esclarecidos. Entretanto, sabe-se que alguns mecanismos fisiológicos incluem a participação de surfactantes pulmonares, a 
depuração mucociliar e a fagocitose de partículas inaladas, fatores essenciais para a homeostase das vias aéreas. ${ }^{13,88}$

As células epiteliais das vias aéreas, incluindo os pneumócitos tipo I e tipo II, macrófagos alveolares e os granulócitos ou células polimorfonucleares são as células responsáveis pela imunidade inata nas vias aéreas que coordenam essas funções fisiológicas e respondem rapidamente ao entrar em contato com o aerossol. Sendo os macrófagos alveolares encarregados da fagocitose e degradação dos diferentes vapores inalados, patógenos e células apoptóticas, que seria o processo chamado eferocitose, para auxiliar na diminuição da resposta inflamatória nos tecidos danificados. E a sua atividade de limpeza é suprimida quando exposta aos vapores, que alteram o fenótipo e a função dos macrófagos alveolares. Consequentemente, a diminuição da depuração celular prejudicará a resolução da inflamação. Além disso, estão desequilibrados os mecanismos de reparo celular e a depuração mucociliar das vias aéreas. ${ }^{88}$

Outra alteração observada nos usuários de cigarro eletrônico é a redução da função pulmonar, medida pelo volume expiratório forçado no primeiro segundo (VEF1) e pela relação entre o volume expiratório forçado e a capacidade vital forçada (VEF/CVF). Também foi relatado importante aumento em MUC4, uma mucina ancorada na membrana, e um aumento proporcional de mucinas secretórias MUC5AC para MUC5B comparado com não fumantes. Ademais, foi visto que as proteínas do complexo inflamassoma, caspase-1 e proteína semelhante a speck associada à apoptose contendo ativação de caspase e domínio de recrutamento, que promovem a piroptose celular, estão elevadas no fluido do lavado broncoalveolar de usuários de cigarro eletrônico. ${ }^{88,89}$

Apesar dos cigarros eletrônicos não possuírem o alcatrão em sua composição, há a adição de outros componentes e, como consequência, diferentes mecanismos de lesão pulmonar. Dentre eles a queimadura térmica pelo vapor aquecido na combustão do líquido, o acúmulo de lipídios no pulmão devido aos aditivos ricos em óleo, a reação alérgica ou até mesmo pneumonia eosinofílica, a pneumonia de hipersensibilidade ou por lesão tóxica dada diretamente pelos produtos químicos contidos no vapor. Além da nicotina, há ainda outros aditivos, aromatizantes, óleos essenciais e de tetrahidrocanabinol que são adicionados à composição do líquido e, por consequência, estão presentes no vapor aerossolizado do cigarro eletrônico. ${ }^{7}$ 
Husari A. et al. realizou um estudo no qual propõe diferentes mecanismos de lesão pulmonar aguda em relação ao cigarro eletrônico e o cigarro tradicional. Assim, a literatura e o estudo sugerem que o cigarro tradicional está associado ao estresse oxidativo decorrente da exposição à radicais livres, alterando o equilíbrio oxidativo. Ademais, foi evidenciado que o estresse oxidativo é mediado pela IL-6 e IL-8 e que a morte celular programada estão associados ao cigarro eletrônico. 89,90

Sabe-se que a saúde pulmonar é afetada pelo uso de cigarros eletrônicos. Assim, a literatura mostra que o aumento da nicotina originado da fumaça do cigarro interrompe a função microvascular da barreira pulmonar. Esse mecanismo ocorre pela ativação de células endoteliais e pela reorganização do citoesqueleto. ${ }^{91}$

Diante disso, a manutenção de uma barreira endotelial preservada é dada pelo equilíbrio das forças de contração do citoesqueleto e pela integridade dos contatos célula a célula. Dessa forma, a absorção de nicotina promove a interrupção dessa barreira, e como consequência, aumenta a contração da actomiosina pela fosforilação dependente de Rho quinase, que promove a inibição da miosina fosfatase endotelial, aumentando a fosforilação da cadeia leve de miosina. ${ }^{92}$

Além disso, a nicotina é facilmente absorvida através da pele, mucosas, vias respiratórias, vias aéreas e trato gastrointestinal, o que pode ocasionar um envenenamento pela exposição excessiva à substância. ${ }^{11}$

No meio microscópico, os extratos que contêm nicotina possuem, somados ao veículo, propilenoglicol e à glicerina, com um potencial de remodelamento das vias aéreas, por meio de uma irritação na mucosa oral e nasal e, também metaplasia de células escamosas. Podendo ainda induzir mecanismos de eliminação, incluindo recrutamento de células inflamatórias. ${ }^{20,92,93,94}$

O CC16 (proteína 16 da célula surfactante) é uma proteína anti-inflamatória, produzida exclusivamente nas células colunares não ciliadas dos grandes e pequenos brônquios e bronquíolos do pulmão. Ela reduz a inflamação das vias aéreas e o estresse oxidativo, além de sequestrar algumas substâncias nocivas que podem ser depositadas no pulmão. Entretanto, os mecanismos responsáveis pelas variações séricas de CC16 são complexos e se baseiam na alteração na permeabilidade epitelial alveolar, morte das club cells e mudanças na transcrição dentro das club cells restantes. Diante disso, o aumento dos níveis séricos de $\mathrm{CC} 16$ após a vaporização representa uma disfunção epitelial, podendo prejudicar a homeostase do fluido 
respiratório e das trocas gasosas pulmonares. Essa perturbação também afeta o componente vascular, culminando com vazamento da $\mathrm{CC16}$ do pulmão para a corrente sanguínea. ${ }^{92}$

O diacetil (DA; 2-3-butanodiona) e o acetato de vitamina E são encontrados tanto em alimentos quanto no cigarro eletrônico. Quando ingeridos, não ocasionam nenhum dano, em contrapartida, quando inalados, o DA é capaz de causar lesão epitelial, diminuindo transitoriamente a resistência elétrica transepitelial. Já o acetato de vitamina $E$ interfere na função fisiológica pulmonar ao entrar em contato com fosfolipídeos e surfactantes do fluido de revestimento epitelial. ${ }^{88,95}$

Figura 4: A lesão das células basais das vias aéreas provocadas pela exposição do diacetil

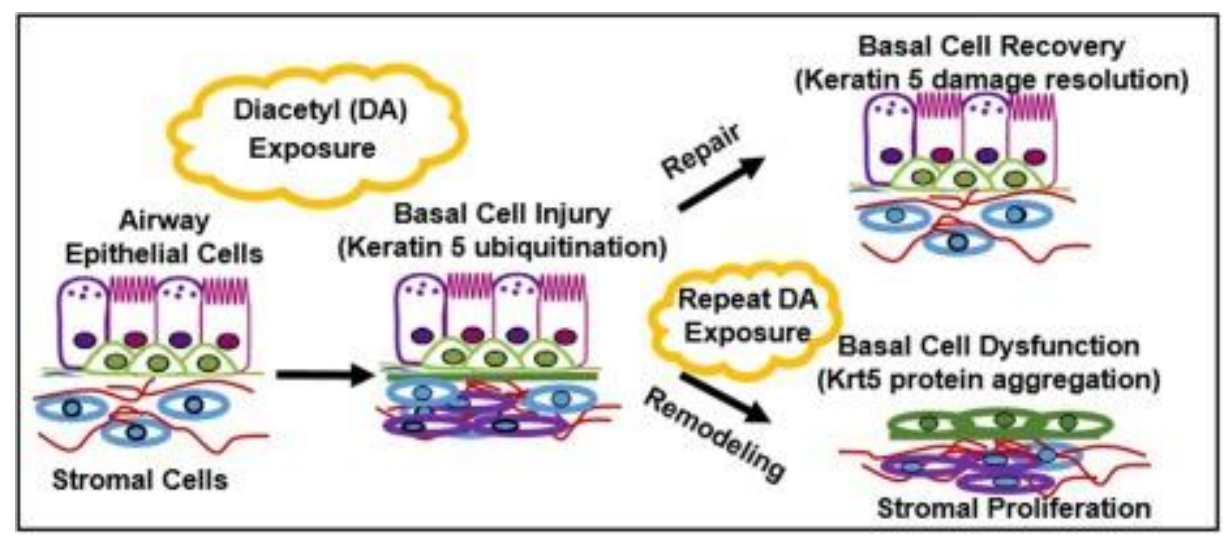

Fonte:Airway basal cell injury after acute diacetyl (2,3-butanedione) vapor exposure ${ }^{95}$

Outro fato acerca do acetato de vitamina E é a sua contribuição para a ocorrência de pneumonia lipoide, que é devido à ingredientes contendo lipídeos ou óleos aerossolizados nas vias aéreas, desencadeando um processo inflamatório e comprometimento de função. Isso ocorre, mais detalhadamente, pela interação dos óleos com a membrana de surfactante pulmonar. ${ }^{29,94,96}$

Ademais, os isômeros da vitamina $E$ exercem efeitos regulatórios sobre a proteína quinase $\mathrm{C}$ a (PKCa) nas células endoteliais respiratórias, determinando o recrutamento de leucócitos, fase importante no desencadeamento de uma resposta exacerbada das vias aéreas e de inflamação pulmonar. Esse mecanismo associado a outros efeitos deletérios do vaping promovem modificações do epitélio respiratório (transição epitelial para mesenquimal) e do seu potencial carcinogênico. ${ }^{97}$

O estudo de Lee et al. (2018) está entre os primeiros estudos a indicar que as nitrosaminas e metabólitos derivados da nicotina encontrados na fumaça dos cigarros 
eletrônicos colocam os fumantes em um risco maior de desenvolver câncer de pulmão ou bexiga ou doenças cardíacas do que os não fumantes. ${ }^{89}$

\subsection{APRESENTAÇÕES CLÍNICAS}

A apresentação clínica da maioria dos pacientes consiste em sinais e sintomas respiratórios (tosse, dispneia, síndrome do desconforto respiratório) e gastrointestinais (náusea, vômitos, diarreia) e alguns inespecíficos, como febre. Podem ser identificados, ao exame físico, sinais de taquicardia, taquipneia e hipóxia (com saturação de oxigênio abaixo de $95 \%$ ou menor). ${ }^{16,18,19,98}$

Os quadros costumam evoluir rapidamente, necessitando de intubação e ventilação mecânica (principalmente em regime de pressão positiva) em cuidados na unidade de terapia intensiva. ${ }^{16,98}$

Os padrões de lesões pulmonares associadas ao "vaping" são mais frequentemente observados os seguintes: pneumonite fibrinosa aguda, dano alveolar difuso e uma mistura de outros processos de doenças, como hemorragia alveolar, pneumonia lipóide e pneumonia eosinofílica aguda. ${ }^{5}$

\subsection{DIAGNÓSTICO}

O EVALI é um diagnóstico de exclusão pela inexistência de um teste ou marcador específico. Entretanto, é importante suspeitar de pacientes que apresentem histórico de uso ou familiares e conhecidos próximos que utilizam esses dispositivos. ${ }^{17,} 19$

As lesões pulmonares relacionadas com essa doença são definidas pela presença de infiltrados pulmonares na imagem; pelo uso de sistemas eletrônicos de entrega de nicotina nos últimos 90 dias; ter ausência de outras causas possíveis, como infecção, cardíaca, neoplásica ou reumatológica; e, por fim, ter ausência de diagnóstico plausível alternativo. 1, 2, 14, 22

Portanto, a avaliação deve incluir a exclusão de outros processos infecciosos pulmonares. Para isso, podemos realizar os seguintes exames: radiografia ou tomografia computadorizada de tórax, cultura de escarro, hemocultura, broncoscopia com lavagem broncoalveolar, biópsias transbrônquicas e testes sorológicos. ${ }^{2,14}$

Diante disso, os exames de imagem são os mais utilizados para auxiliarem o diagnóstico, apresentando alguns padrões mais comuns e que também podem ser 
encontrados em outras doenças. O padrão descrito mais prevalentemente encontrado é o de vidro fosco bilateralmente em lobos inferiores e opacidades consolidadas subpleurais. Sendo menos frequentes os derrames pleurais (raros), opacidades densas na base (como observadas na síndrome do desconforto respiratório agudo) e opacidades consolidadas difusas e irregulares e confluentes (como observadas na pneumonia em organização criptogênica) ou opacidades em vidro fosco do lobo superior com aprisionamento de ar (como observado em pneumonite de hipersensibilidade). Dependendo da intensidade dos esforços de inalação associados ao vaping, o pneumotórax e o pneumomediastino são raramente vistos. ${ }^{2,}$ 14, 20, 98

Além disso, as biópsias realizadas nos casos de lesão pulmonar associada ao produto e-cigarro ou vaping mostraram lesão pulmonar aguda, manifestando-se como pneumonia em organização, dano alveolar difuso, pneumonia lipóide, pneumonite fibrinosa aguda ou uma combinação desses padrões. A avaliação citopatológica de amostras de lavado broncoalveolar revelou macrófagos espumosos e vacuolização de pneumócitos, que foram positivos para Oil Red $\mathrm{O}$, consistentes com o acúmulo de lipídios, o que pode estar relacionado à glicerina contida nos líquidos aerossolizados, produzindo um padrão semelhante ao pulmão induzido por amiodarona lesão com fosfolipidose endógena. ${ }^{13,14}$

Figura 5: Imagens radiológicas das lesões causadas pelo EVALI

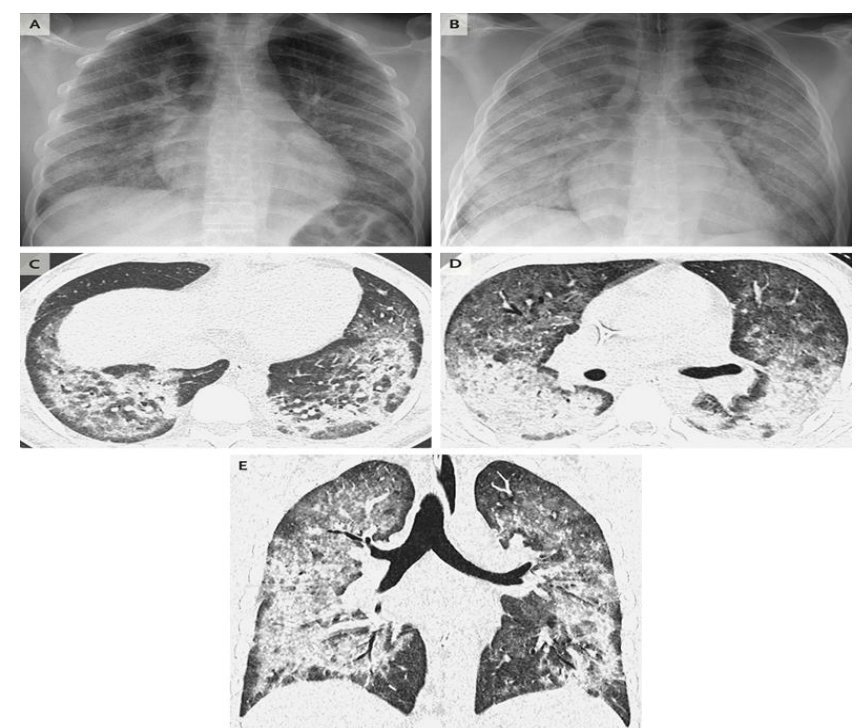

Fonte: Pulmonary IIIness Related to E-Cigarette Use in Illinois and Wisconsin - Final Report 2020 
Os diagnósticos diferenciais estão relacionados com doenças que apresentem sintomas respiratórios similares, como a influenza e outras infecções respiratórias, por exemplo, a pneumonia adquirida na comunidade. ${ }^{17}$

\subsection{TRATAMENTO}

É fundamental que os pacientes em uso do cigarro eletrônico sejam orientados quanto às estratégias de cessação do tabagismo, além de aconselhamento comportamental. Essas recomendações auxiliam os pacientes a interromper o uso do vaping antes da piora do quadro ou de futuras complicações. ${ }^{99}$

Os pacientes diagnosticados com EVALI ou classificados como casos suspeitos devem realizar uma radiografia de tórax e é recomendado a internação daqueles com saturação de oxigênio menor 95\% em ar ambiente ou com problemas respiratórios. ${ }^{99}$

A maioria dos pacientes necessitará de intervenções de cuidados intensivos, incluindo pressão positiva não invasiva nas vias aéreas, pressores cardiotônicos e intubação/ventilação mecânica. Sendo a ventilação mecânica uma importante estratégia de proteção pulmonar, especialmente quando há risco de progressão para a Síndrome do Desconforto Respiratório Agudo (SDRA). Finalmente, uma abordagem multidisciplinar é vital para melhorar as chances de sobrevivência na unidade de terapia intensiva. Além disso, o suporte à oxigenação por membrana extracorpórea pode ser necessário em alguns casos. ${ }^{13,} 99$

A terapia empírica agressiva com corticosteróides, antimicrobiana e antiviral se mostraram úteis no tratamento dessa doença e podem ser necessárias para pacientes com doença grave. ${ }^{99}$

A maioria dos pacientes necessitou de tratamento na unidade de terapia intensiva, com melhora em 1-2 semanas da apresentação inicial após a interrupção do vaping e a administração de corticosteróides sistêmicos, quando necessário. ${ }^{18}$

Os esteróides sistêmicos têm sido utilizados em vários casos considerados adequados pelo médico prescritor. Neste momento, não está claro se os esteróides são benéficos. É imperativo monitorar a lesão pulmonar induzida por ventilador, especialmente quando a deterioração clínica justifica medidas mais agressivas. A sobredistensão dos alvéolos devido à pressão expiratória final positiva alta (PEEP) ou ao volume corrente alto pode levar ao volutrauma, e simultaneamente uma pressão 
excessiva nas vias aéreas pode resultar em pneumotórax. Da mesma forma, o oxigênio deve ser titulado para uma tensão arterial mínima de oxigênio de $65 \mathrm{~mm} \mathrm{Hg}$ para reduzir o risco de toxicidade do oxigênio. A avaliação da mecânica pulmonar precisa ser obrigatória. Ferramentas importantes como pressão de condução, balão esofágico e índice de estresse podem nos fornecer informações críticas sobre as necessidades do paciente. $O$ gerenciamento deve ser personalizado e adaptado à fisiologia de cada paciente. A posição prona precisa ser implementada quando indicada sem atraso, bem como bloqueio neuromuscular. Restrição de líquidos e nutrição adequada são cruciais. Além disso, os profissionais de saúde devem estar atentos a complicações sobrepostas, como pneumonia associada à ventilação mecânica. Implementando estratégias como o pacote ABCDEF e coordenar o atendimento multidisciplinar deve ser a pedra angular da gestão. ${ }^{13}$

Para evitar que pacientes com EVALI sejam reinternados ou morram após a alta por uma hospitalização é necessário que as orientações incluam: 1) confirmação de flutuações clinicamente significativas nos sinais vitais por pelo menos 24 a 48 horas antes da alta; 2) garantia de atendimento primário ambulatorial ou acompanhamento de especialista pulmonar, idealmente dentro de 48 horas após a alta (previamente recomendado dentro de 2 semanas após a alta); 3) planejamento para cuidados de alta, acompanhamento precoce e gerenciamento de quaisquer comorbidades; 4) providenciar atendimento especializado pós-hospitalização; 5) seguir as melhores práticas para adesão a medicamentos; e 6) garantir apoio social e acesso aos serviços de saúde mental e comportamental e transtorno do uso de substâncias. ${ }^{100}$

É fundamental a reavaliação do paciente pós-alta por uma equipe multidisciplinar, podendo ser realizado por meio de visitas domiciliares através de agentes comunitários de saúde, pelo agendamento de consultas ambulatoriais e até mesmo por ligações ou mensagens de texto. ${ }^{100}$

Além disso, o acompanhamento ambulatorial auxilia na prevenção de reinternações, resultando em menores taxas de complicações e de evolução a óbito. ${ }^{100}$

Com base nos dados do Centers of Disease Control and Prevention (CDC), foi visto que além da reavaliação do paciente pós-alta e do acompanhamento ambulatorial, algumas orientações são recomendadas. São elas:

- avaliar sinais vitais, exame físico, resolução ou sintomas e testes laboratoriais; 
- promover educação continuada sobre EVALI;

- garantir a adesão aos regimes de medicação, como redução dos corticosteroides (se prescritos no momento da alta hospitalar);

- reforçar a importância da abstinência do uso do produto e-cigarro, ou vaporização;

- facilitar a conexão ao atendimento ambulatorial por todos os provedores ou serviços indicados pelo histórico médico do paciente ou condições;

- conectar os pacientes aos recursos sociais, de saúde mental e de transtorno de uso de substâncias necessários; e

- estabelecer conexão com os serviços necessários. ${ }^{100,101}$

\section{CONCLUSÃO}

O uso do cigarro eletrônico é uma nova forma de tabagismo emergente, principalmente em indivíduos jovens, não isento de malefícios à saúde. O EVALI é uma síndrome de lesão pulmonar aguda, com manifestações importantes, inclusive risco de morte.

\section{REFERÊNCIAS}

1- Hooper RW 2nd, Garfield JL. An Emerging Crisis: Vaping-Associated Pulmonary Injury. Ann Intern Med. 2020 Jan 7;172(1):57-58. doi: 10.7326/M19-2908. Epub 2019 Oct 8. PMID: 31590182. Disponível em< https://www.acpjournals.org/doi/10.7326/M19-2908> Acesso em:03 Oct 2020

2- Mukhopadhyay S, Mehrad M, Dammert P, Arrossi AV, Sarda R, Brenner DS, Maldonado F, Choi H, Ghobrial M. Lung Biopsy Findings in Severe Pulmonary IIIness Associated With E-Cigarette Use (Vaping). Am J Clin Pathol. 2020 Jan 1;153(1):30-39. doi: 10.1093/ajcp/aqz182. PMID: 31621873. Disponível em< https://academic.oup.com/ajcp/article/153/1/30/5588493> Acesso em:03 Oct 2020

3- Christiani DC. Vaping-Induced Acute Lung Injury. N Engl J Med. 2020 Mar 5;382(10):960-962. doi: 10.1056/NEJMe1912032. Epub 2019 Sep 6. PMID: 31491071. Disponível em< https://www.nejm.org/doi/10.1056/NEJMe1912032

https://pediatrics.aappublications.org/content/146/1/e20194104> Acesso em:03 Oct 2020

4- Ghinai I, Layden JE. Web Exclusive. Annals for Hospitalists Inpatient Notes - Clinical Pearls-ECigarette, or Vaping, Product Use-Associated Lung Injury. Ann Intern Med. 2019 Dec 17;171(12):HO2-HO3. doi: 10.7326/M19-3574. PMID: 31842218. Disponível em< https://www.acpjournals.org/doi/10.7326/M19-3574>Acesso em:03 Oct 2020

5- Miskoff JA, Chaudhri M. E-cigarette or Vaping Product Use-associated Lung Injury: A Case of an Adult Female Leading to Hospitalization. Cureus. 2020 Jan 24;12(1):e6765. doi: 10.7759/cureus.6765. PMID: 32140332; PMCID: PMC7039348.Disponível $\quad$ em< 
https://www.cureus.com/articles/26823-e-cigarette-or-vaping-product-use-associated-lung-injury-acase-of-an-adult-female-leading-to-hospitalization> Acesso em:03 Oct 2020.

6- Abeles M, Popofsky S, Wen A, Valsamis C, Webb A, Halaby C, Pirzada M. Vaping-associated lung injury caused by inhalation of cannabis oil. Pediatr Pulmonol. 2020 Jan;55(1):226-228. doi: 10.1002/ppul.24579. Epub 2019 Nov 20. PMID: 31746559. Disponível em<https://onlinelibrary.wiley.com/doi/full/10.1002/ppul.24579> Acesso em:03 Oct 2020

7- Boland JM, Aesif SW. Vaping-Associated Lung Injury. Am J Clin Pathol. 2020 Jan 1;153(1):1-2. doi: 10.1093/ajcp/aqz191. PMID: 31651033. Disponível em<https://academic.oup.com/ajcp/articleabstract/153/1/1/5606633?redirectedFrom=fulltext> Acesso em:03 Oct 2020

8- Cirulis MM, Callahan SJ, Aberegg SK. Marijuana Legislation and Electronic Cigarette- or VapingAssociated Lung Injury: A Historical Perspective. JAMA Netw Open. 2020 Apr 1;3(4):e202238. doi: 10.1001/jamanetworkopen.2020.2238. PMID: 32250430. Disponível em <https://jamanetwork.com/journals/jamanetworkopen/fullarticle/2763965> Acesso em: 03 Oct 2020.

9- Alexander LEC, Perez MF. Identifying, tracking, and treating lung injury associated with ecigarettes or vaping. Lancet. 2019 Dec 7;394(10214):2041-2043. doi: 10.1016/S0140-6736(19)327308. Epub 2019 Nov 8. PMID: 31711628. Disponível em<https://www.thelancet.com/journals/lancet/article/PIIS0140-6736(19)32730-8/fulltext> Acesso em:03 Oct 2020

10- Kooragayalu S, El-Zarif S, Jariwala S. Vaping Associated Pulmonary Injury (VAPI) with superimposed Mycoplasma pneumoniae infection. Respiratory Medicine Case Reports. 2020 ;29:100997. DOI: 10.1016/j.rmcr.2020.100997. Disponível $\quad$ em< https://www.sciencedirect.com/science/article/pii/S2213007119303120?via\%3Dihub>Acesso em:03 Oct 2020

11- Meo SA, Al Asiri SA. Effects of electronic cigarette smoking on human health. Eur Rev Med Pharmacol Sci. 2014;18(21):3315-9. PMID: 25487945. Disponível $\quad$ em< https://pubmed.ncbi.nlm.nih.gov/25487945/> Acesso em:03 Oct 2020

12- The Lancet. E-cigarettes: time to realign our approach? Lancet. 2019 Oct 12;394(10206):1297. doi: 10.1016/S0140-6736(19)32277-9. PMID: 31609211. Disponível $\quad$ em< https://www.thelancet.com/journals/lancet/article/PIIS0140-6736(19)32277-9/fulltext> Acesso em:03 Oct 2020

13- Fonseca Fuentes X, Kashyap R, Hays JT, Chalmers S, Lama von Buchwald C, Gajic O, Gallo de Moraes A. VpALI-Vaping-related Acute Lung Injury: A New Killer Around the Block. Mayo Clin Proc. 2019 Dec;94(12):2534-2545. doi: 10.1016/j.mayocp.2019.10.010. Epub 2019 Nov 22. PMID: 31767123. Disponível em<https://www.mayoclinicproceedings.org/article/S0025-6196(19)308808/fulltext> Acesso em:03 Oct 2020

14- Cherian SV, Kumar A, Estrada-Y-Martin RM. E-Cigarette or Vaping Product-Associated Lung Injury: A Review. Am J Med. 2020 Jun;133(6):657-663. doi: 10.1016/j.amjmed.2020.02.004. Epub 2020 Mar $\quad$ 13. $\quad$ PMID: $32179055 . \quad$ Disponível $\quad$ em< https://linkinghub.elsevier.com/retrieve/pii/S0002934320301406> Acesso em:03 Oct 2020 
15- Moritz ED, Zapata LB, Lekiachvili A, Glidden E, Annor FB, Werner AK, Ussery EN, Hughes MM, Kimball A, DeSisto CL, Kenemer B, Shamout M, Garcia MC, Reagan-Steiner S, Petersen EE, Koumans EH, Ritchey MD, King BA, Jones CM, Briss PA, Delaney L, Patel A, Polen KD, Sives K, Meaney-Delman D, Chatham-Stephens K; Lung Injury Response Epidemiology/Surveillance Group; Lung Injury Response Epidemiology/Surveillance Task Force. Update: Characteristics of Patients in a National Outbreak of E-cigarette, or Vaping, Product Use-Associated Lung Injuries - United States, October 2019. MMWR Morb Mortal Wkly Rep. 2019 Nov 1;68(43):985-989. doi: 10.15585/mmwr.mm6843e1. Erratum in: MMWR Morb Mortal Wkly Rep. 2019 Dec 20;68(50):1170. PMID: $\quad 31671085 ; \quad$ PMCID: $\quad$ PMC6822806. Disponível em<https://www.cdc.gov/mmwr/volumes/68/wr/mm6843e1.htm?s_cid=mm6843e1_w> Acesso em:03 Oct 2020

16- Ind PW. E-cigarette or vaping product use-associated lung injury. $\mathrm{Br} \mathrm{J}$ Hosp Med (Lond). 2020 Apr 2;81(4):1-9. doi: 10.12968/hmed.2019.0371. Epub 2020 Apr 8. PMID: 32339005. Disponível em < https://www.magonlinelibrary.com/doi/full/10.12968/hmed.2019.0371 > Acesso em: 03 Oct 2020 17- Jatlaoui TC, Wiltz JL, Kabbani S, Siegel DA, Koppaka R, Montandon M, Adkins SH, Weissman DN, Koumans EH, O'Hegarty M, O'Sullivan MC, Ritchey MD, Chatham-Stephens K, Kiernan EA, Layer M, Reagan-Steiner S, Legha JK, Shealy K, King BA, Jones CM, Baldwin GT, Rose DA, Delaney LJ, Briss $P$, Evans ME; Lung Injury Response Clinical Working Group. Update: Interim Guidance for Health Care Providers for Managing Patients with Suspected E-cigarette, or Vaping, Product UseAssociated Lung Injury - United States, November 2019. MMWR Morb Mortal Wkly Rep. 2019 Nov 22;68(46):1081-1086. doi: 10.15585/mmwr.mm6846e2. PMID: 31751322; PMCID: PMC6871902. Disponível em<https://www.cdc.gov/mmwr/volumes/68/wr/mm6846e2.htm?s_cid=mm6846e2_w> Acesso em:03 Oct 2020

18- Kalininskiy A, Bach CT, Nacca NE, Ginsberg G, Marraffa J, Navarette KA, McGraw MD, Croft DP. E-cigarette, or vaping, product use associated lung injury (EVALI): case series and diagnostic approach. Lancet Respir Med. 2019 Dec;7(12):1017-1026. doi: 10.1016/S2213-2600(19)30415-1.

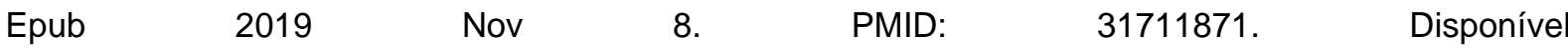
em<https://linkinghub.elsevier.com/retrieve/pii/S2213260019304151> Acesso em:03 Oct 2020 19- Blagev DP, Harris D, Dunn AC, Guidry DW, Grissom CK, Lanspa MJ. Clinical presentation, treatment, and short-term outcomes of lung injury associated with e-cigarettes or vaping: a prospective observational cohort study. Lancet. 2019 Dec 7;394(10214):2073-2083. doi: 10.1016/S0140-6736(19)32679-0. Epub 2019 Nov 8. PMID: 31711629. Disponível em<https://www.thelancet.com/journals/lancet/article/PIIS0140-6736(19)32679-0/fulltext> Acesso em:03 Oct 2020

20- Balmes JR. Vaping-induced Acute Lung Injury: An Epidemic That Could Have Been Prevented. Am J Respir Crit Care Med. 2019 Dec 1;200(11):1342-1344. doi: 10.1164/rccm.2019101903ED. PMID: 31613146; PMCID: PMC6884057. Disponível em< https://www.atsjournals.org/doi/10.1164/rccm.201910-1903ED> Acesso em:03 Oct 2020 21- Krishnasamy VP, Hallowell BD, Ko JY, Board A, Hartnett KP, Salvatore PP, Danielson M, KitePowell A, Twentyman E, Kim L, Cyrus A, Wallace M, Melstrom P, Haag B, King BA, Briss P, Jones CM, 
Pollack LA, Ellington S; Lung Injury Response Epidemiology/Surveillance Task Force. Update: Characteristics of a Nationwide Outbreak of E-cigarette, or Vaping, Product Use-Associated Lung Injury - United States, August 2019-January 2020. MMWR Morb Mortal Wkly Rep. 2020 Jan 24;69(3):90-94. doi: 10.15585/mmwr.mm6903e2. PMID: 31971931; PMCID: PMC7367698. Disponível em < https://www.cdc.gov/mmwr/volumes/69/wr/mm6903e2.htm?s_cid=mm6903e2_w> Acesso em: 03 Oct 2020

22- S.E. Pambuccian.Testing for lipid-laden macrophages in bronchoalveolar lavage fluid to diagnose vaping-associated pulmonary injury. Are we there yet?J Am Soc Cytopathol, 9 (2020), pp. 1-8 em < https://doi.org/10.1016/j.jasc.2019.10.002> Acesso em: 03 Oct 2020

23- Griffiths A, Rauzi A, Stadheim K, Wheeler W. Lung Injury Associated with E-Cigarette or Vaping Product Use. Pediatr Ann. 2020 Feb 1;49(2):e93-e98. doi: 10.3928/19382359-20200120-01. PMID: 32045489. Disponível em< https://www.healio.com/pediatrics/journals/pedann/2020-2-492/\%7Be7216945-2b33-4c83-aee6-6232e56f8876\%7D/lung-injury-associated-with-e-cigarette-orvaping-product-use > Acesso em:03 Oct 2020

24- Ali M, Khan K, Buch M, Ramos-Ramirez M, Sharma M, Patel S, Choudhury S, Anjum H, Khan A, Surani S. A Case Series of Vaping-Induced Lung Injury in a Community Hospital Setting. Case Rep Pulmonol. 2020 Jan 31;2020:9631916. doi: 10.1155/2020/9631916. PMID: 32082682; PMCID: PMC7013298.Disponível em< https://www.hindawi.com/journals/cripu/2020/9631916/> Acesso em:03 Oct 2020.

25- Puebla Neira D, Tambra S, Bhasin V, Nawgiri R, Duarte AG. Discordant bilateral bronchoalveolar lavage findings in a patient with acute eosinophilic pneumonia associated with counterfeit tetrahydrocannabinol oil vaping. Respir Med Case Rep. 2020 Feb 3;29:101015. doi: 10.1016/j.rmcr.2020.101015. PMID: 32071854; PMCID: PMC7013172. Disponível em< https://www.sciencedirect.com/science/article/pii/S2213007119304095?via\%3Dihub> Acesso em:03 Oct 2020

26- Gutsche J, Pasternak R, Campbell D, Schili JL, Boyle PJ, Tilney P. A 19-Year-Old Man With Vaping-Associated Lung Injury. Air Med J. 2020 Jan-Feb;39(1):6-8. doi: 10.1016/j.amj.2019.12.002. Epub 2019 Dec 28. PMID: 32044072 .Disponível $\quad$ em< https://linkinghub.elsevier.com/retrieve/pii/S1067991X19302494> Acesso em:03 Oct 2020 27- Blagev DP. No man is an island: e-cigarette, or vaping, associated lung injury in Europe. Eur Respir J. 2020 Feb 6;55(2):1902419. doi: 10.1183/13993003.02419-2019. PMID: 32029647. Disponível em < https://erj.ersjournals.com/content/55/2/1902419> Acesso em: 03 Oct 2020

28- DeCarli K, Arabiat M, Ward C, Levinson A, Carino G. A Case of Vaping-Associated Lung Injury in Rhode Island. R I Med J (2013). 2020 Feb 3;103(1):38-41. PMID: 32013304. Disponível em< https://pubmed.ncbi.nlm.nih.gov/32013304/> Acesso em:03 Oct 2020

29- Priemer DS, Gravenmier C, Batouli A, Hooper JE. Overview of Pathologic Findings of Vaping in the Context of an Autopsy Patient With Chronic Injury. Arch Pathol Lab Med. 2020 May 8. doi: 10.5858/arpa.2019-0637-RA. Epub ahead of print. PMID: 32383974. Disponível em< https://meridian.allenpress.com/aplm/article/doi/10.5858/arpa.2019-0637-RA/442270/Overview-ofPathologic-Findings-of-Vaping-in-the> Acesso em:03 Oct 2020 
30- Kass AP, Overbeek DL, Chiel LE, Boyer EW, Casey AMH. Case series: Adolescent victims of the vaping public health crisis with pulmonary complications. Pediatr Pulmonol. 2020 May;55(5):1224-1236. doi: 10.1002/ppul.24729. Epub 2020 Mar 13. PMID: 32168438. Disponível em <https://onlinelibrary.wiley.com/doi/abs/10.1002/ppul.24729> Acesso em: 03 Oct 2020

31- Rao DR, Maple KL, Dettori A, Afolabi F, Francis JKR, Artunduaga M, Lieu TJ, Aldy K, Cao DJ, Hsu S, Feng SY, Mittal V. Clinical Features of E-cigarette, or Vaping, Product Use-Associated Lung Injury in Teenagers. Pediatrics. 2020 Jul;146(1):e20194104. doi: 10.1542/peds.2019-4104. Epub 2020 May 11. PMID: 32393606. Disponível em<> Acesso em:03 Oct 2020

32- Villeneuve T, Prevot G, Le Borgne A, Colombat M, Collot S, Ruiz S, Lanot T, Brouchet L, Rabeau A, Noel-Savina E, Didier A. Diffuse alveolar haemorrhage secondary to e-cigarette "vaping" associated lung injury (EVALI) in a young European consumer. Eur Respir J. $2020 \mathrm{Jul}$ 16;56(1):2000143. doi: 10.1183/13993003.00143-2020. PMID: 32265304. Disponível em< https://erj.ersjournals.com/content/56/1/2000143> Acesso em:03 Oct 2020

33- Messina MD, Levin TL, Conrad LA, Bidiwala A. Vaping associated lung injury: A potentially lifethreatening epidemic in US youth. Pediatr Pulmonol. 2020 Jul;55(7):1705-1711. doi: 10.1002/ppul.24755. Epub 2020 Apr 6. PMID: 32251551. Disponível em< https://onlinelibrary.wiley.com/doi/abs/10.1002/ppul.24755> Acesso em:03 Oct 2020

34- Aldy K, Cao DJ, McGetrick M, Willcutts D, Verbeck G, De Silva I, Hsu S. Severe E-Cigarette, or Vaping, Product Use Associated Lung Injury Requiring Venovenous Extracorporeal Membrane Oxygenation. Pediatr Crit Care Med. 2020 Apr;21(4):385-388. doi: 10.1097/PCC.0000000000002264. PMID: $\quad 32150124 . \quad$ Disponível em< https://journals.Iww.com/pccmjournal/Abstract/2020/04000/Severe_E_Cigarette,_or_Vaping,_Product_ Use.11.aspx> Acesso em:03 Oct 2020

35- Fryman C, Lou B, Weber AG, Steinberg HN, Khanijo S, lakovou A, Makaryus MR. Acute Respiratory Failure Associated With Vaping. Chest. 2020 Mar;157(3):e63-e68. doi: 10.1016/j.chest.2019.10.057. PMID: 32145818. Disponível em< https://journal.chestnet.org/article/S0012-3692(19)34387-9/fulltext> Acesso em:03 Oct 2020 36- Israel AK, Velez MJ, Staicu SA, Ambrosini R, McGraw M, Agrawal T. A Unique Case of Secondary Pulmonary Alveolar Proteinosis after E-Cigarette, or Vaping, Product Use-associated Lung Injury. Am J Respir Crit Care Med. 2020 Sep 15;202(6):890-893. doi: 10.1164/rccm.202002-0252LE. PMID: 32392077. Disponível em< https://www.atsjournals.org/doi/10.1164/rccm.202002-0252LE> Acesso em:03 Oct 2020

37- Sakla NM, Gattu R, Singh G, Sadler M. Vaping-associated acute respiratory distress syndrome. Emerg Radiol. 2020 Feb;27(1):103-106. doi: 10.1007/s10140-019-01736-6. Epub 2019 Dec 9. PMID: 31820270. Disponível em < https://link.springer.com/article/10.1007\%2Fs10140-019-01736-6

> Acesso em: 03 Oct 2020

38- Conuel EJ, Chieng HC, Fantauzzi J, Pokhrel K, Goldman C, Smith TC, Tiwari A, Chopra A, Judson MA. Cannabinoid Oil Vaping-Associated Lung Injury and its Radiographic Appearance. Am J Med. 2020 Jul;133(7):865-867. doi: 10.1016/j.amjmed.2019.10.032. Epub 2019 Nov 18. PMID: 
31751528. Disponível em < https://linkinghub.elsevier.com/retrieve/pii/S0002934319309763> Acesso em: 03 Oct 2020

39- Layden JE, Ghinai I, Pray I, Kimball A, Layer M, Tenforde MW, Navon L, Hoots B, Salvatore PP, Elderbrook M, Haupt T, Kanne J, Patel MT, Saathoff-Huber L, King BA, Schier JG, Mikosz CA, Meiman J. Pulmonary IIIness Related to E-Cigarette Use in Illinois and Wisconsin - Final Report. N Engl J Med. 2020 Mar 5;382(10):903-916. doi: 10.1056/NEJMoa1911614. Epub 2019 Sep 6. PMID: 31491072. Disponível em < https://www.nejm.org/doi/10.1056/NEJMoa1911614 > Acesso em: 03 Oct 2020 40- Ocampo-Gonzalez FA, Park JW. Cytologic features of vaping-induced lung injury: A case report. Diagn Cytopathol. 2020 Feb;48(2):174-176. doi: 10.1002/dc.24343. Epub 2019 Nov 12. PMID: 31714032. Disponível em< https://onlinelibrary.wiley.com/doi/abs/10.1002/dc.24343> Acesso em:03 Oct 2020

41- Deliwala S, Sundus S, Haykal T, Theophilus N, Bachuwa G. E-cigarette, or Vaping, Product Useassociated Lung Injury (EVALI): Acute Lung Illness within Hours of Switching from Traditional to E-cigarettes. Cureus. 2020 Apr 2;12(4):e7513. doi: 10.7759/cureus.7513. PMID: 32373415; PMCID: PMC7195202. Disponível em < https://www.cureus.com/articles/29440-e-cigarette-or-vaping-productuse-associated-lung-injury-evali-acute-lung-illness-within-hours-of-switching-from-traditional-to-ecigarettes > Acesso em: 01 Nov 2020

42- Freathy $S$, Kondapalli N, Patlolla S, Mora A, Trimmer $C$. Acute lung injury secondary to ecigarettes or vaping. Proc (Bayl Univ Med Cent). 2019 Dec 23;33(2):227-228. doi: 10.1080/08998280.2019.1705225. PMID: 32313466; PMCID: PMC7155998. Disponível em < https://www.tandfonline.com/doi/abs/10.1080/08998280.2019.1705225?journalCode=ubmc20> Acesso em: 01 Nov 2020

43- Carroll BJ, Kim M, Hemyari A, Thakrar P, Kump TE, Wade T, De Vela G, Hall J, Diaz CD, D'Andrea LA. Impaired lung function following e-cigarette or vaping product use associated lung injury in the first cohort of hospitalized adolescents. Pediatr Pulmonol. 2020 Jul;55(7):1712-1718. doi: 10.1002/ppul.24787. Epub 2020 Apr 22. PMID: 32320538. Disponível em< https://onlinelibrary.wiley.com/doi/abs/10.1002/ppul.24787> Acesso em:03 Oct 2020

44- Matta P, Hamati JN, Unno HL, Fox MD. E-cigarette or Vaping Product Use-Associated Lung Injury (EVALI) Without Respiratory Symptoms. Pediatrics. 2020 May;145(5):e20193408. doi: 10.1542/peds.2019-3408. Epub 2020 Apr 21. PMID: 32317307. Disponível em< https://pediatrics.aappublications.org/content/145/5/e20193408> Acesso em:03 Oct 2020 45- Triantafyllou GA, Tiberio PJ, Zou RH, Lamberty PE, Lynch MJ, Kreit JW, Gladwin MT, Morris A, Chiarchiaro J. Vaping-associated Acute Lung Injury: A Case Series. Am J Respir Crit Care Med. 2019 Dec 1;200(11):1430-1431. doi: 10.1164/rccm.201909-1809LE. PMID: 31574235. Disponível em < https://www.atsjournals.org/doi/10.1164/rccm.201909-1809LE > Acesso em: 01 Nov 2020 46- Marlière C, De Greef J, Gohy S, Hoton D, Wallemacq P, Jacquet LM, Belkhir L. Fatal e-cigarette or vaping associated lung injury (EVALI): a first case report in Europe. Eur Respir J. $2020 \mathrm{Jul}$ 30;56(1):2000077. doi: 10.1183/13993003.00077-2020. PMID: 32217651. Disponível em< https://erj.ersjournals.com/content/56/1/2000077> Acesso em:03 Oct 2020 
47- Ahmad M, Aftab G, Rehman S, Frenia D. Long-term Impact of E-cigarette and Vaping Product Use-associated Lung Injury on Diffusing Capacity for Carbon Monoxide Values: A Case Series. Cureus. 2020 Feb 15;12(2):e7002. doi: 10.7759/cureus.7002. PMID: 32206466; PMCID: PMC7077067. Disponível em< https://www.cureus.com/articles/26302-long-term-impact-of-e-cigarette-and-vapingproduct-use-associated-lung-injury-on-diffusing-capacity-for-carbon-monoxide-values-a-case-series> Acesso em:03 Oct 2020

48- Gay B, Field Z, Patel S, Alvarez RM, Nasser W, Madruga M, Carlan SJ. Vaping-Induced Lung Injury: A Case of Lipoid Pneumonia Associated with E-Cigarettes Containing Cannabis. Case Rep Pulmonol. 2020 Apr 3;2020:7151834. doi: 10.1155/2020/7151834. PMID: 32309002; PMCID: PMC7157807. Disponível em< https://www.hindawi.com/journals/cripu/2020/7151834/> Acesso em:03 Oct 2020

49- Billa R, Tigges C, Vijayakumar N, Radke J, Pedati C, Weiner R, McCabe D. E-Cigarette, or Vaping, Product Use Associated Lung Injury (EVALI) with Acute Respiratory Failure in Three Adolescent Patients: a Clinical Timeline, Treatment, and Product Analysis. J Med Toxicol. 2020 Jul;16(3):248254. doi: 10.1007/s13181-020-00765-9. Epub 2020 Mar 19. PMID: 32193828; PMCID: PMC7095090. Disponível em < https://link.springer.com/article/10.1007\%2Fs13181-020-00765-9 > Acesso em: 01 Nov 2020

50- Choe J, Chen P, Falk JA, Nguyen L, Ng D, Parimon T, Ghandehari S. A Case Series of VapingAssociated Lung Injury Requiring Mechanical Ventilation. Crit Care Explor. 2020 Jan 29;2(1):e0079. doi: 10.1097/CCE.0000000000000079. PMID: 32166299; PMCID: PMC7063900. Disponível $\mathrm{em}<$ https://journals.Iww.com/ccejournal/Fulltext/2020/01000/A_Case_Series_of_Vaping_Associated_Lung _Injury.11.aspx> Acesso em:03 Oct 2020

51- Itoh M, Aoshiba K, Herai $Y$, Nakamura $H$, Takemura $T$. Lung injury associated with electronic cigarettes inhalation diagnosed by transbronchial lung biopsy. Respirol Case Rep. 2017 Nov 17;6(1):e00282. doi: 10.1002/rcr2.282. PMID: 29321926; PMCID: PMC5757588.Disponível em< https://onlinelibrary.wiley.com/doi/full/10.1002/rcr2.282> Acesso em:03 Oct 2020

52- He T, Oks M, Esposito M, Steinberg H, Makaryus M. "Tree-in-Bloom": Severe Acute Lung Injury Induced by Vaping Cannabis Oil. Ann Am Thorac Soc. 2017 Mar;14(3):468-470. doi: 10.1513/AnnalsATS.201612-974LE. $\quad$ PMID: 28248584. Disponível em< https://www.atsjournals.org/doi/10.1513/AnnalsATS.201612-974LE> Acesso em:03 Oct 2020 53- Salzman GA, Alqawasma M, Asad H. Vaping Associated Lung Injury (EVALI): An Explosive United States Epidemic. Mo Med. 2019 Nov-Dec;116(6):492-496. PMID: 31911735; PMCID: PMC6913849. Disponível em< https://pubmed.ncbi.nlm.nih.gov/31911735/> Acesso em:03 Oct 2020 54- Singh A, Tan Q, Saccone NM, Lindner DH. A Case of Vaping TCH Oil Leading to Vaping Associated Pulmonary Injury: Our Approach to Its Diagnosis, Management, and Recommendations. Case Rep Pulmonol. 2020 Jan 4;2020:6138083. doi: 10.1155/2020/6138083. PMID: $\quad 31976113$; $\quad$ PMCID: $\quad$ PMC6968930. Disponível em< https://www.hindawi.com/journals/cripu/2020/6138083/> Acesso em:03 Oct 2020 
55- Ansari-Gilani K, Petraszko AM, Teba CV, Reeves AR, Gupta A, Gupta A, Ramaiya NH, Gilkeson $\mathrm{RC}$. E-cigarette use related lung disease, review of clinical and imaging findings in $\mathbf{3}$ cases. Heart Lung. 2020 Mar-Apr;49(2):139-143. doi: 10.1016/j.hrtlng.2020.01.005. Epub 2020 Jan 31. PMID: 32008808. Disponível em< https://pubmed.ncbi.nlm.nih.gov/32008808/> Acesso em:03 Oct 2020 56- Macias AE, Garcia FJ, Saldana SG. A patient from Mexico with vaping-associated lung injury, seizures and renal failure. Tob Induc Dis. 2019 Dec 11;17:91. doi: 10.18332/tid/114316. PMID: 31892921; PMCID: PMC6915431. Disponível em< http://www.tobaccoinduceddiseases.org/A-patientfrom-Mexico-with-vaping-associated-lung-injury-seizures-and-renal-failure,114316,0,2.html> Acesso em:03 Oct 2020

57- Aftab G, Ahmad M, Frenia D. Vaping-associated Lung Injury. Cureus. 2019 Nov 22;11(11):e6216. doi: 10.7759/cureus.6216. PMID: 31890417; PMCID: PMC6929261. Disponível em< https://www.cureus.com/articles/24705-vaping-associated-lung-injury> Acesso em:03 Oct 2020 58- Youmans AJ, Harwood J. Gross and Histopathological Findings in the First Reported VapingInduced Lung Injury Death in the United States. Am J Forensic Med Pathol. 2020 Mar;41(1):1-4. doi: 10.1097/PAF.0000000000000533. PMID: 31977349. Disponível em< https://journals.Iww.com/amjforensicmedicine/Abstract/2020/03000/Gross_and_Histopathological_Find ings_in_the_First.1.aspx> Acesso em:03 Oct 2020

59- Casanova GS, Amaro R, Soler N, Sánchez M, Badía JR, Barberà JA, Agustí A. An imported case of e-cigarette or vaping associated lung injury in Barcelona. Eur Respir J. 2020 Feb 6;55(2):1902076. doi: 10.1183/13993003.02076-2019. PMID: 31806720. Disponível em <https://erj.ersjournals.com/content/55/2/1902076> Acesso em: 01 Nov 2020

60- Wilhite R, Patel T, Karle E, Shankar S, Krvavac A. Diffuse Alveolar Hemorrhage: An Uncommon Manifestation of Vaping-associated Lung Injury. Cureus. 2019 Dec 31;11(12):e6519. doi: 10.7759/cureus.6519. PMID: 32025438; PMCID: PMC6991143.Disponível em< https://www.cureus.com/articles/26089-diffuse-alveolar-hemorrhage-an-uncommon-manifestation-ofvaping-associated-lung-injury> Acesso em:03 Oct 2020

61- Artunduaga M, Rao D, Friedman J, Kwon JK, Pfeifer CM, Dettori A, Winant AJ, Lee EY. Pediatric Chest Radiographic and CT Findings of Electronic Cigarette or Vaping Product Use-associated Lung Injury (EVALI). Radiology. 2020 May;295(2):430-438. doi: 10.1148/radiol.2020192778. Epub 2020 Mar 3. PMID: 32125258. Disponível em < https://pubs.rsna.org/doi/10.1148/radiol.2020192778> Acesso em: 03 Oct 2020

62- Pray IW, Atti SK, Tomasallo C, Meiman JG. E-cigarette, or Vaping, Product Use-Associated Lung Injury Among Clusters of Patients Reporting Shared Product Use - Wisconsin, 2019. MMWR Morb Mortal Wkly Rep. 2020 Mar 6;69(9):236-240. doi: 10.15585/mmwr.mm6909a4. PMID: 32134907; PMCID: $\quad$ PMC7367091. Disponível em < https://www.cdc.gov/mmwr/volumes/69/wr/mm6909a4.htm?s_cid=mm6909a4_w> Acesso em: 03 Oct 2020

63- Navon L, Jones CM, Ghinai I, King BA, Briss PA, Hacker KA, Layden JE. Risk Factors for ECigarette, or Vaping, Product Use-Associated Lung Injury (EVALI) Among Adults Who Use ECigarette, or Vaping, Products - Illinois, July-October 2019. MMWR Morb Mortal Wkly Rep. 2019 
Nov 15;68(45):1034-1039. doi: 10.15585/mmwr.mm6845e1. PMID: 31725708; PMCID: PMC6855514. Disponível em< https://www.cdc.gov/mmwr/volumes/68/wr/mm6845e1.htm?s_cid=mm6845e1_w $>$ Acesso em:03 Oct 2020

64- Blount BC, Karwowski MP, Morel-Espinosa M, Rees J, Sosnoff C, Cowan E, Gardner M, Wang L, Valentin-Blasini L, Silva L, De Jesús VR, Kuklenyik Z, Watson C, Seyler T, Xia B, Chambers D, Briss P, King BA, Delaney L, Jones CM, Baldwin GT, Barr JR, Thomas J, Pirkle JL. Evaluation of Bronchoalveolar Lavage Fluid from Patients in an Outbreak of E-cigarette, or Vaping, Product Use-Associated Lung Injury - 10 States, August-October 2019. MMWR Morb Mortal Wkly Rep. 2019 Nov 15;68(45):1040-1041. doi: 10.15585/mmwr.mm6845e2. Erratum in: MMWR Morb Mortal Wkly Rep. 2020 Jan 31;69(4):116. PMID: 31725707; PMCID: PMC6855513. Disponível em< https://www.cdc.gov/mmwr/volumes/68/wr/mm6845e2.htm?s_cid=mm6845e2_w> Acesso em:03 Oct 2020

65- Lewis N, McCaffrey K, Sage K, Cheng CJ, Green J, Goldstein L, Campbell H, Ferrell D, Malan N, LaCross N, Maldonado A, Board A, Hanchey A, Harris D, Callahan S, Aberegg S, Risk I, Willardson S, Carter A, Nakashima A, Duncan J, Burnett C, Atkinson-Dunn R, Dunn A. E-cigarette Use, or Vaping, Practices and Characteristics Among Persons with Associated Lung Injury - Utah, April-October 2019. MMWR Morb Mortal Wkly Rep. 2019 Oct 25;68(42):953-956. doi: 10.15585/mmwr.mm6842e1. PMID: $\quad 31647788$; PMCID: PMC6812834. Disponível em < https://www.cdc.gov/mmwr/volumes/68/wr/mm6842e1.htm?s_cid=mm6842e1_w> Acesso em: 03 Oct 2020

66- Perrine CG, Pickens CM, Boehmer TK, King BA, Jones CM, DeSisto CL, Duca LM, Lekiachvili A, Kenemer B, Shamout M, Landen MG, Lynfield R, Ghinai I, Heinzerling A, Lewis N, Pray IW, Tanz LJ, Patel A, Briss PA; Lung Injury Response Epidemiology/Surveillance Group. Characteristics of a Multistate Outbreak of Lung Injury Associated with E-cigarette Use, or Vaping - United States, 2019. MMWR Morb Mortal Wkly Rep. 2019 Oct 4;68(39):860-864. doi: 10.15585/mmwr.mm6839e1. Erratum in: MMWR Morb Mortal Wkly Rep. 2019 Oct 11;68(40):900. PMID: 31581168; PMCID: PMC6776378.

Disponível em https://www.cdc.gov/mmwr/volumes/68/wr/mm6839e1.htm?s_cid=mm6839e1_w > Acesso em: 03 Oct 2020

67- Ghinai I, Pray IW, Navon L, O'Laughlin K, Saathoff-Huber L, Hoots B, Kimball A, Tenforde MW, Chevinsky JR, Layer M, Ezike N, Meiman J, Layden JE. E-cigarette Product Use, or Vaping, Among Persons with Associated Lung Injury - Illinois and Wisconsin, April-September 2019. MMWR Morb Mortal Wkly Rep. 2019 Oct 4;68(39):865-869. doi: 10.15585/mmwr.mm6839e2. PMID: 31581166; PMCID: PMC6776374. Disponível em < https://www.cdc.gov/mmwr/volumes/68/wr/mm6839e2.htm?s_cid=mm6839e2_w > Acesso em: 03 Oct 2020

68- Schier JG, Meiman JG, Layden J, Mikosz CA, VanFrank B, King BA, Salvatore PP, Weissman DN, Thomas J, Melstrom PC, Baldwin GT, Parker EM, Courtney-Long EA, Krishnasamy VP, Pickens CM, Evans ME, Tsay SV, Powell KM, Kiernan EA, Marynak KL, Adjemian J, Holton K, Armour BS, England LJ, Briss PA, Houry D, Hacker KA, Reagan-Steiner S, Zaki S, Meaney-Delman D; CDC 2019 Lung Injury 
Response Group. Severe Pulmonary Disease Associated with Electronic-Cigarette-Product Use Interim Guidance. MMWR Morb Mortal Wkly Rep. 2019 Sep 13;68(36):787-790. doi: 10.15585/mmwr.mm6836e2. Erratum in: MMWR Morb Mortal Wkly Rep. 2019 Sep 27;68(38):830. PMID: 31513561; PMCID: PMC6755818. Disponível em < https://pubmed.ncbi.nlm.nih.gov/31513561/ > Acesso em: 03 Oct 2020

69- Davidson K, Brancato A, Heetderks P, Mansour W, Matheis E, Nario M, Rajagopalan S, Underhill B, Wininger J, Fox D. Outbreak of Electronic-Cigarette-Associated Acute Lipoid Pneumonia North Carolina, July-August 2019. MMWR Morb Mortal Wkly Rep. 2019 Sep 13;68(36):784-786. doi: 10.15585/mmwr.mm6836e1. PMID: 31513559; PMCID: PMC6755817. Disponível em < https://www.cdc.gov/mmwr/volumes/68/wr/mm6836e1.htm?s_cid=mm6836e1_w> Acesso em: 03 Oct 2020

70- Alexander LEC, Bellinghausen $\mathrm{AL}$, Eakin $\mathrm{MN}$. What are the mechanisms underlying vapinginduced lung injury? J Clin Invest. 2020 Jun 1;130(6):2754-2756. doi: 10.1172/JCl138644. PMID: 32391805; PMCID: PMC7260008. Disponível em < https://www.jci.org/articles/view/138644 > Acesso em: 03 Oct 2020

71- Dawod YT, Cook NE, Graham WB, Madhani-Lovely F, Thao C. Smoking-associated interstitial lung disease: update and review. Expert Rev Respir Med. 2020 Aug;14(8):825-834. doi: 10.1080/17476348.2020.1766971. Epub 2020 May 22. PMID: 32379511. Disponível em < https://www.tandfonline.com/doi/full/10.1080/17476348.2020.1766971> Acesso em: 03 Oct 2020

72- Foust AM, Winant AJ, Chu WC, Das KM, Phillips GS, Lee EY. Pediatric SARS, H1N1, MERS, EVALI, and Now Coronavirus Disease (COVID-19) Pneumonia: What Radiologists Need to Know. AJR Am J Roentgenol. 2020 Sep;215(3):736-744. doi: 10.2214/AJR.20.23267. Epub 2020 Apr 30. PMID: 32352308. Disponível em < https://www.ajronline.org/doi/10.2214/AJR.20.23267 > Acesso em: 03 Oct 2020

73- Werner AK, Koumans EH, Chatham-Stephens K, Salvatore PP, Armatas C, Byers P, Clark CR, Ghinai I, Holzbauer SM, Navarette KA, Danielson ML, Ellington S, Moritz ED, Petersen EE, Kiernan EA, Baldwin GT, Briss P, Jones CM, King BA, Krishnasamy V, Rose DA, Reagan-Steiner S; Lung Injury Response Mortality Working Group. Hospitalizations and Deaths Associated with EVALI. N Engl J Med. 2020 Apr 23;382(17):1589-1598. doi: 10.1056/NEJMoa1915314. PMID: 32320569. Disponível em < https://www.nejm.org/doi/10.1056/NEJMoa1915314 > Acesso em: 03 Oct 2020

74- Cao DJ, Aldy K, Hsu S, McGetrick M, Verbeck G, De Silva I, Feng SY. Review of Health Consequences of Electronic Cigarettes and the Outbreak of Electronic Cigarette, or Vaping, Product Use-Associated Lung Injury. J Med Toxicol. 2020 Jul;16(3):295-310. doi: 10.1007/s13181020-00772-w. Epub 2020 Apr 16. PMID: 32301069; PMCID: PMC7320089. Disponível em < https://link.springer.com/article/10.1007\%2Fs13181-020-00772-w> Acesso em: 03 Oct 2020

75- Muthumalage T, Friedman MR, McGraw MD, Ginsberg G, Friedman AE, Rahman I. Chemical Constituents Involved in E-Cigarette, or Vaping Product Use-Associated Lung Injury (EVALI). Toxics. 2020 Apr 3;8(2):25. doi: 10.3390/toxics8020025. PMID: 32260052; PMCID: PMC7355865. Disponível em < https://www.mdpi.com/2305-6304/8/2/25 > Acesso em: 03 Oct 2020 
76- Nelson B. Vaping, lung damage, and cytopathology: A new twist in the medical mystery: Accumulating evidence has clarified the role of cytopathology in the diagnosis of vapingassociated lung injuries and implicated vitamin $E$ acetate as a likely culprit. Cancer Cytopathol. 2020 Mar;128(3):153-154. doi: 10.1002/cncy.22257. PMID: 32141713. Disponível em <https://acsjournals.onlinelibrary.wiley.com/doi/full/10.1002/cncy.22257> Acesso em: 03 Oct 2020 77- Shahab L, Britton J, Brown J, Hajek P, McNeill A; 33 signatories. The need for an evidence-based and rational debate on e-cigarettes. Lancet. 2020 Feb 29;395(10225):688. doi: 10.1016/S01406736(20)30113-6. PMID: 32113501. Disponível em < https://www.thelancet.com/journals/lancet/article/PIIS0140-6736(20)30113-6/fulltext> Acesso em: 03 Oct 2020

78- Kalkhoran S, Chang Y, Rigotti N. Correction to: Online Searches for Quitting Vaping During the 2019 Outbreak of E-cigarette or Vaping Product Use-Associated Lung Injury. J Gen Intern Med. 2020 Mar 6. doi: 10.1007/s11606-020-05753-x. Epub ahead of print. Erratum for: J Gen Intern Med. 2020 Feb 12;: PMID: 32144693. Disponível em < https://link.springer.com/article/10.1007\%2Fs11606020-05686-5> Acesso em: 03 Oct 2020

79- Gaub KL, Hallyburton S, Samanic C, Paddack D, Clark CR, Pence S, Brown JA, Hawkins E. Patient Characteristics and Product Use Behaviors Among Persons with E-cigarette, or Vaping, Product Use-Associated Lung Injury - Indiana, June-October 2019. MMWR Morb Mortal Wkly Rep. 2019 Dec 13;68(49):1139-1141. doi: 10.15585/mmwr.mm6849a3. PMID: 31830007; PMCID: PMC6919291. Disponível em < https://www.cdc.gov/mmwr/volumes/68/wr/mm6849a3.htm?s_cid=mm6849a3_w> Acesso em: 03 Oct 2020

80- Kligerman S, Raptis C, Larsen B, Henry TS, Caporale A, Tazelaar H, Schiebler ML, Wehrli FW, Klein JS, Kanne J. Radiologic, Pathologic, Clinical, and Physiologic Findings of Electronic Cigarette or Vaping Product Use-associated Lung Injury (EVALI): Evolving Knowledge and Remaining Questions. Radiology. 2020 Mar;294(3):491-505. doi: 10.1148/radiol.2020192585. Epub 2020 Jan 28. PMID: 31990264.Disponível em< https://pubs.rsna.org/doi/10.1148/radiol.2020192585> Acesso em:03 Oct 2020

81- Saqi A, Mukhopadhyay S, Butt Y, Doxtader E, Heymann JJ, Larsen BT, Moreira AL, Patel A, Reynolds JP, Sung S, Crapanzano JP. E-cigarette or vaping product use-associated lung injury: What is the role of cytologic assessment? Cancer Cytopathol. 2020 Jun;128(6):371-380. doi: 10.1002/cncy.22237. Epub 2020 Jan 27. PMID: 31985892. Disponível em< https://acsjournals.onlinelibrary.wiley.com/doi/abs/10.1002/cncy.22237> Acesso em:03 Oct 2020 82- Ellington S, Salvatore PP, Ko J, Danielson M, Kim L, Cyrus A, Wallace M, Board A, Krishnasamy V, King BA, Rose D, Jones CM, Pollack LA; Lung Injury Response Epidemiology/Surveillance Task 83- Force. Update: Product, Substance-Use, and Demographic Characteristics of Hospitalized Patients in a Nationwide Outbreak of E-cigarette, or Vaping, Product Use-Associated Lung Injury - United States, August 2019-January 2020. MMWR Morb Mortal Wkly Rep. 2020 Jan 17;69(2):4449. doi: 10.15585/mmwr.mm6902e2. PMID: 31945038; PMCID: PMC6973348.Disponível em< https://www.cdc.gov/mmwr/volumes/69/wr/mm6902e2.htm?s_cid=mm6902e2_w> Acesso em:03 Oct 2020 
84- Balmes JR. Reply to Eissenberg and Maziak: Are Electronic Cigarette Users at Risk for Lipidmediated Lung Injury? Am J Respir Crit Care Med. 2020 Apr 15;201(8):1013-1014. doi: 10.1164/rccm.201912-2499LE. PMID: 31917603; PMCID: PMC7159429. Disponível em < https://www.atsjournals.org/doi/10.1164/rccm.201912-2499LE > Acesso em: 03 Oct 2020

85- Lozier MJ, Wallace B, Anderson K, Ellington S, Jones CM, Rose D, Baldwin G, King BA, Briss P, Mikosz CA; Lung Injury Response Epidemiology/Surveillance Task Force. Update: Demographic, Product, and Substance-Use Characteristics of Hospitalized Patients in a Nationwide Outbreak of E-cigarette, or Vaping, Product Use-Associated Lung Injuries - United States, December 2019. MMWR Morb Mortal Wkly Rep. 2019 Dec 13;68(49):1142-1148. doi: 10.15585/mmwr.mm6849e1. Erratum in: MMWR Morb Mortal Wkly Rep. 2020 Jan 31;69(4):117. PMID: 31830008; PMCID: PMC6919288. Disponível em < https://www.cdc.gov/mmwr/volumes/68/wr/mm6849e1.htm?s_cid=mm6849e1_w > Acesso em: 03 Oct 2020

86- Hartnett KP, Kite-Powell A, Patel MT, Haag BL, Sheppard MJ, Dias TP, King BA, Melstrom PC, Ritchey MD, Stein Z, Idaikkadar N, Vivolo-Kantor AM, Rose DA, Briss PA, Layden JE, Rodgers L, Adjemian J. Syndromic Surveillance for E-Cigarette, or Vaping, Product Use-Associated Lung Injury. N Engl J Med. 2020 Feb 20;382(8):766-772. doi: 10.1056/NEJMsr1915313. Epub 2019 Dec 20. PMID: 31860794 . Disponível em < https://www.nejm.org/doi/10.1056/NEJMsr1915313 > Acesso em: 03 Oct 2020

87- Saji S, Patil SS, Alleyn M, Lockey R, Kolliputi N. Nicotine in E-cigarette smoke: cancer culprit? J Cell Commun Signal. 2020 Mar;14(1):127-128. doi: 10.1007/s12079-019-00519-5. Epub 2019 Dec 18. PMID: 31853716; PMCID: PMC7176775.Disponível em<https://www.nejm.org/doi/10.1056/NEJMsr1915313 >Acesso em:03 Oct 2020

88- Chand HS, Muthumalage T, Maziak W, Rahman I. Pulmonary Toxicity and the Pathophysiology of Electronic Cigarette, or Vaping Product, Use Associated Lung Injury. Front Pharmacol. 2020 Jan 14;10:1619. doi: 10.3389/fphar.2019.01619. PMID: 31992985; PMCID: PMC6971159.Disponível em< https://www.frontiersin.org/articles/10.3389/fphar.2019.01619/full> Acesso em:03 Oct 2020 89- Singh KP, Lawyer G, Muthumalage T, Maremanda KP, Khan NA, McDonough SR, Ye D, Mclntosh $S$, Rahman I. Systemic biomarkers in electronic cigarette users: implications for noninvasive assessment of vaping-associated pulmonary injuries. ERJ Open Res. 2019 Dec 23;5(4):001822019. doi: 10.1183/23120541.00182-2019. PMID: 31886159; PMCID: PMC6926365. Disponível em< https://openres.ersjournals.com/content/5/4/00182-2019Acesso em:03 Oct 2020

90- Husari A, Shihadeh A, Talih S, Hashem Y, El Sabban M, Zaatari G. Acute Exposure to Electronic and Combustible Cigarette Aerosols: Effects in an Animal Model and in Human Alveolar Cells. Nicotine Tob Res. 2016 May;18(5):613-9. doi: 10.1093/ntr/ntv169. Epub 2015 Aug 13. PMID: 26272212; PMCID: PMC5942611. Disponível em< https://academic.oup.com/ntr/article/18/5/613/2510832> Acesso em:03 Oct 2020

91- Schweitzer KS, Chen SX, Law S, Van Demark M, Poirier C, Justice MJ, Hubbard WC, Kim ES, Lai X, Wang M, Kranz WD, Carroll CJ, Ray BD, Bittman R, Goodpaster J, Petrache I. Endothelial disruptive proinflammatory effects of nicotine and e-cigarette vapor exposures. Am $\mathrm{J}$ Physiol 
Lung Cell Mol Physiol. 2015 Jul 15;309(2):L175-87. doi: 10.1152/ajplung.00411.2014. Epub 2015 May 15. PMID: 25979079; PMCID: PMC4504977. Disponível em< https://journals.physiology.org/doi/full/10.1152/ajplung.00411.2014> Acesso em:03 Oct 2020 92- Chaumont M, van de Borne P, Bernard A, Van Muylem A, Deprez G, Ullmo J, Starczewska E, Briki $\mathrm{R}$, de Hemptinne $\mathrm{Q}$, Zaher W, Debbas $\mathrm{N}$. Fourth generation e-cigarette vaping induces transient lung inflammation and gas exchange disturbances: results from two randomized clinical trials. Am J Physiol Lung Cell Mol Physiol. 2019 May 1;316(5):L705-L719. doi: 10.1152/ajplung.00492.2018. Epub 2019 Feb 6. PMID: 30724099; PMCID: PMC6589591. Disponível em< https://journals.physiology.org/doi/full/10.1152/ajplung.00492.2018> Acesso em:03 Oct 2020 93- Hamberger ES, Halpern-Felsher B. Vaping in adolescents: epidemiology and respiratory harm. Curr Opin Pediatr. 2020 Jun;32(3):378-383. doi: 10.1097/MOP.0000000000000896. PMID: 32332328; PMCID: $\quad$ PMC7285995. Disponível $\quad$ em $<\quad$ https://journals.Iww.com/copediatrics/Abstract/2020/06000/Vaping_in_adolescents_epidemiology_and.9.aspx> Acesso em:03 Oct 2020.

94- Winnicka L, Shenoy MA. EVALI and the Pulmonary Toxicity of Electronic Cigarettes: A Review. J Gen Intern Med. 2020 Jul;35(7):2130-2135. doi: 10.1007/s11606-020-05813-2. Epub 2020 Apr 3. PMID: $\quad 32246394 ; \quad$ PMCID: $\quad$ PMC7351931. Disponível $\quad$ em< https://link.springer.com/article/10.1007/s11606-020-05813-2>Acesso em:03 Oct 2020 95- McGraw MD, Kim SY, Reed C, Hernady E, Rahman I, Mariani TJ, Finkelstein JN. Airway basal cell injury after acute diacetyl (2,3-butanedione) vapor exposure. Toxicol Lett. 2020 Jun 1;325:25-33. doi: 10.1016/j.toxlet.2020.02.012. Epub 2020 Feb 26. PMID: 32112875; PMCID: PMC7164319. Disponível em< https://www.sciencedirect.com/science/article/pii/S0378427420300618?via\%3Dihub> Acesso em:03 Oct 2020

96- Boudi FB, Patel S, Boudi A, Chan C. Vitamin E Acetate as a Plausible Cause of Acute Vapingrelated Illness. Cureus. 2019 Dec 11;11(12):e6350. doi: 10.7759/cureus.6350. PMID: 31938636; PMCID: PMC6952050. Disponível em< https://www.cureus.com/articles/25498-vitamin-e-acetate-as-aplausible-cause-of-acute-vaping-related-illness> Acesso em:03 Oct 2020

97- Lal A, Mishra AK, Sahu KK. Vitamin E Acetate and E-Cigarette or Vaping Product-Associated Lung Injury (EVALI): An Update. Am J Med. 2020 May;133(5):e204. doi: 10.1016/j.amjmed.2019.11.005. Epub 2019 Dec 28. PMID: 31889515. Disponível em< https://www.amjmed.com/article/S0002-9343(19)31074-5/fulltext> Acesso em:03 Oct 2020

98- Xantus GZ. Vaping-associated lung injury-VALI facts, assumptions and opportunities: review of the present situation. Postgrad Med J. 2020 Feb;96(1132):61-63. doi: 10.1136/postgradmedj-2019137185. Epub 2019 Nov 25. PMID: 31767670. Disponível em< https://pmj.bmj.com/content/96/1132/61> Acesso em:03 Oct 2020

99- Siegel DA, Jatlaoui TC, Koumans EH, Kiernan EA, Layer M, Cates JE, Kimball A, Weissman DN, Petersen EE, Reagan-Steiner S, Godfred-Cato S, Moulia D, Moritz E, Lehnert JD, Mitchko J, London J, Zaki SR, King BA, Jones CM, Patel A, Delman DM, Koppaka R; Lung Injury Response Clinical Working Group; Lung Injury Response Epidemiology/Surveillance Group. Update: Interim Guidance for Health Care Providers Evaluating and Caring for Patients with Suspected E- 
cigarette, or Vaping, Product Use Associated Lung Injury - United States, October 2019. MMWR Morb Mortal Wkly Rep. 2019 Oct 18;68(41):919-927. doi: 10.15585/mmwr.mm6841e3. PMID: 31633675; PMCID: PMC6802682. Disponível em < https://www.cdc.gov/mmwr/volumes/68/wr/mm6841e3.htm?s_cid=mm6841e3_w> Acesso em: 03 Oct 2020

100- Evans ME, Twentyman E, Click ES, Goodman AB, Weissman DN, Kiernan E, Hocevar SA, Mikosz CA, Danielson M, Anderson KN, Ellington S, Lozier MJ, Pollack LA, Rose DA, Krishnasamy V, Jones CM, Briss P, King BA, Wiltz JL; Lung Injury Response Clinical Task Force; Lung Injury Response Clinical Working Group. Update: Interim Guidance for Health Care Professionals Evaluating and Caring for Patients with Suspected E-cigarette, or Vaping, Product Use-Associated Lung Injury and for Reducing the Risk for Rehospitalization and Death Following Hospital Discharge - United States, December 2019. MMWR Morb Mortal Wkly Rep. 2020 Jan 3;68(5152):1189-1194. doi: 10.15585/mmwr.mm685152e2. PMID: 31895915; PMCID: PMC6943965. Disponível em < https://www.cdc.gov/mmwr/volumes/68/wr/mm685152e2.htm?s_cid=mm685152e2_w> Acesso em: 03 Oct 2020

101- Chatham-Stephens K, Roguski K, Jang Y, Cho P, Jatlaoui TC, Kabbani S, Glidden E, Ussery EN, Trivers KF, Evans ME, King BA, Rose DA, Jones CM, Baldwin G, Delaney LJ, Briss P, Ritchey MD; Lung Injury Response Epidemiology/Surveillance Task Force; Lung Injury Response Clinical Task Force. Characteristics of Hospitalized and Nonhospitalized Patients in a Nationwide Outbreak of E-cigarette, or Vaping, Product Use-Associated Lung Injury - United States, November 2019. MMWR Morb Mortal Wkly Rep. 2019 Nov 22;68(46):1076-1080. doi: 10.15585/mmwr.mm6846e1. PMID: 31751326; PMCID: PMC6871898. Disponível em <https://www.cdc.gov/mmwr/volumes/68/wr/mm6846e1.htm?s_cid=mm6846e1_w> Acesso em:03 Oct 2020 